\title{
113. Some Observations on the Vascular System of the Spinal Cord in the Rabbit
}

\author{
Masaichi Kimura and Osamu Tunoda \\ Dept. of Orthopedic Surgery, Faculity of Medicine, Hirosaki University
}

In the present study, mature healthy rabbits were used. Specially made acryric resin was injected into blood vessels and mould specimens of the vessels of the spinal cord were made. We investigated the distribution of the superficial arteries and veins of the cord in the specimen.

Preparation of acryric resin is as follows:



benzoil peroxide (catalyst)............ 2.0

dibutyl phthalate (plasticizer) $\ldots \ldots \ldots \ldots \ldots . \ldots \ldots$

dimetyl aniline (promoter) $\ldots \ldots \ldots \ldots \ldots \ldots \ldots$

Superficial arteries of the cord;

The arteries supplying the cord are derived from the vertebral arteries in the cervical region, intercostal arteries in the thoracic region and lumbal arteries in the lumbal region. The branches from these arteries enter the vertebral canal along the spinal nerve passing through the intervertebral foramina. These give branches to the vertebrae and then reach the cord. The arteries reaching the cord further divide into dorsal and ventral radicular arteries.

The latter radicular arteries run medially to the ventral surface of the cord and bifurcate to the decending and ascending branches. A ventral spinal artery is formed close to the median ventral fissure by the anastomosis of the ascending and descending branches of the adjacent ventral radicular arteries. The ventral spinal artery distributes branches to the ventral surface of the cord and send the central arteries running toward the center of the cord.

Dorsal radicular arteries divide into ascending and descending branches on the dorsolteral surface of the cord. By the anastomosis of the ascending and descending branches of the adjacent radicular arteries, a pair of the dorsal spinal artery are formed of the dorsolateral surface of the cord biltellaly.

The dorsal spinal arteries send branches to the dorsal surface of the cord. Oftmal the dorsal spinal arteries are interrupted in the cervical region because of abscent of the anastomosis of the adjacent radicular arteries.

Number of the radicular arteries are variable. Among the ventral and the dorsal radicular arteries, there are usually specially large one ventral and two dorsal ones. They are the most caudal radicular arteries and are 
usually at the level of the 5 th or the 6 th lumbal nerve root.

Superficial veins of the spinal cord;

There are usually four main longitudinal channels on the surface of the cord.

On the median dorsal surface, the median dorsal spinal vein run over the dorsal median sulcus. This vessel receives most of its venous blood from the dorsal side of the cord and some from the lateral surface. The median dorsal spinal vein is the largest of the four and runs along the whole spinal cord.

On the ventral surface of the cord, the ventral spinal vein runs close to the ventral median fissure. It closely parallels the ventral spinal artery. The ventral spinal vein receives blood from the central veins rising from the ventral median fissure and from many branches from the ventral surface of the cord.

In the cervical region, a pair of the lateral spinal vein run on the lateral surface of the cord.

These superficial veins anastomose dorsal and ventral radicular veins. The venous blood of the cord are drained into the radicural veins and trigeminal sinus. The radicular veins direct into a pair of longitudinal internal vertebral sinus which run the ventral surface of the vertebral canal.

\title{
114. Study of Hemodynamics of the Spinal Cord
} (Part one)

\author{
Yoshiji Nimura and Masanao IKEDA \\ 2nd Surgical Division, Kyoto University School of Medicine
}

The study was made on 40 laminectomized adult dogs. $\mathrm{O}_{2}$-availability as an indicator of focal hemodynamics on the surface of the spinal cord, and evoked potential as an indicator of the neuronal activity of the cord were measured under temporary obliteration of the vertebral, subclavian and common carotid arteries, and aorta, respectively.

Combined obliteration of vertebral and subclavian arteries resulted in ischemic changes over the extent of the cervical thoracic cord, whereas no appreciable change was induced on the spinal cord by obliteration of the bilateral common carotid arteries.

Marked ischemic effect was observed in the lumbar cord by obliteration of the aorta. Obliteration at the lower thoracic aorta was more effective 